\title{
ASO Visual Abstract: Impact of the COVID-19 Pandemic on Breast Cancer Stage at Diagnosis, Presentation, and Patient Management
}

\author{
Jennifer E. Tonneson, MD, FACS ${ }^{1}$, Tanya L. Hoskin, MS $^{2}$, Courtney N. Day, BS $^{2}$, Diane M. Durgan, MD, MPH ${ }^{1}$, \\ Christina A. Dilaveri, $\mathrm{MD}^{3}$, and Judy C. Boughey, MD, FACS ${ }^{1}$ \\ ${ }^{1}$ Division of Breast and Melanoma Surgical Oncology, Department of Surgery, Mayo Clinic, Rochester, MN; ${ }^{2}$ Division of \\ Clinical Trials and Biostatistics, Mayo Clinic, Rochester, MN; ${ }^{3}$ Division of General Internal Medicine, Department of \\ Medicine, Mayo Clinic, Rochester, MN
}

The COVID-19 pandemic forced clinicians to change the way that they thought about breast cancer management when screening programs were temporarily suspended and elective procedures postponed. This paper (https://doi.org/ 10.1245/s10434-021-11088-6) examined stage at breast cancer diagnosis and subsequent breast cancer management comparing patients presenting before and during the COVID-19 pandemic. We found that stage at diagnosis, method of cancer detection, and tumor biology did not differ before or during the COVID-19 pandemic, but that use of neoadjuvant endocrine therapy increased

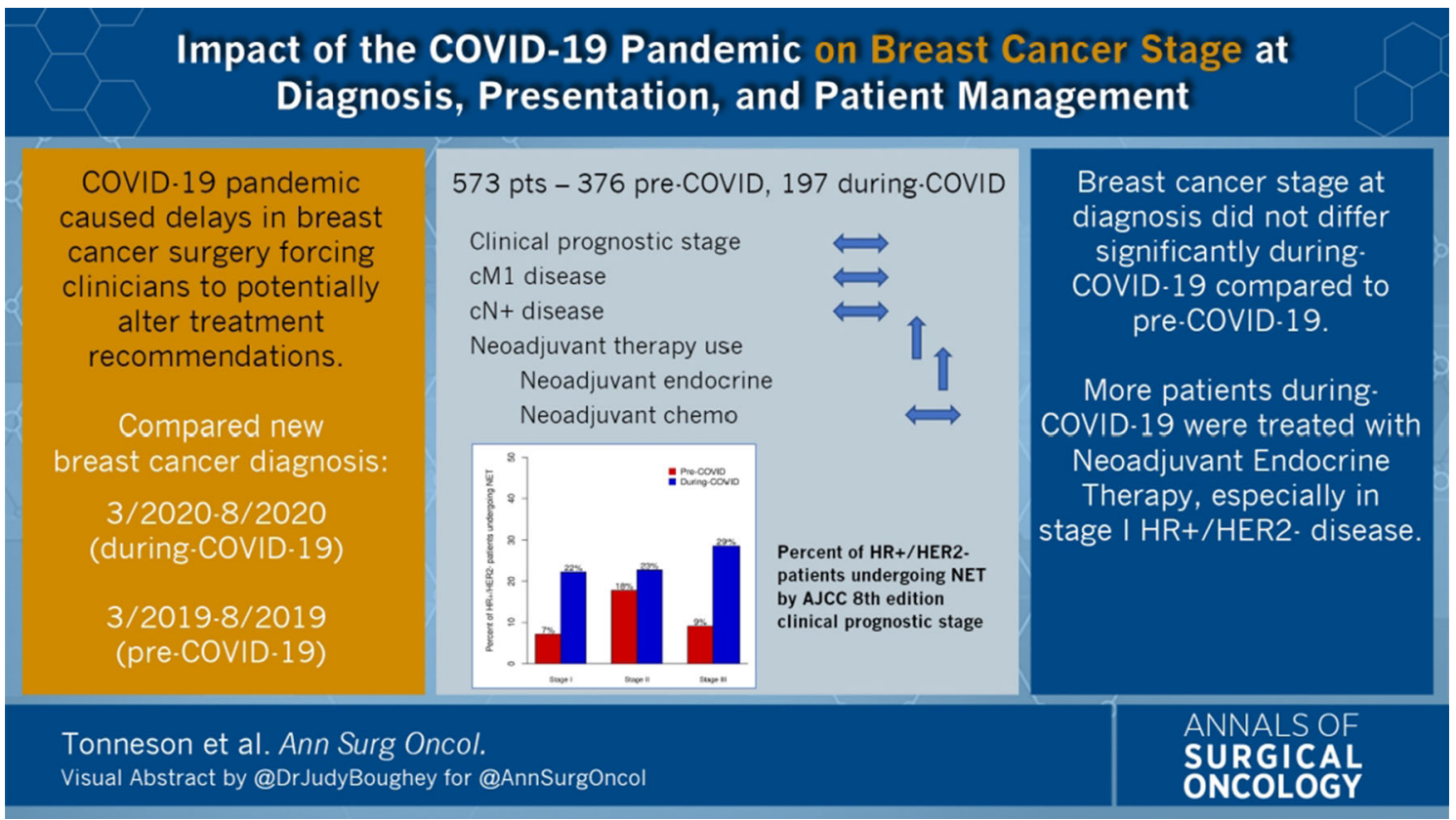

(C) Society of Surgical Oncology 2022

J. C. Boughey, MD, FACS

e-mail: boughey.judy@mayo.edu 
significantly, with significant increased NET use in stage I HR+/HER2 - patients and nonsignificant increases in stage II and III HR+/HER2- patients.

DISCLOSURES Dr. Boughey receives research funding from Lilly for a clinical trial and is on a DSMB for Cairns Surgical.
Publisher's Note Springer Nature remains neutral with regard to jurisdictional claims in published maps and institutional affiliations. 